\title{
CONSERVATION OF EXISTING HOUSING
}

\author{
WILIIAM L. SLAYTON*
}

Conservation as a term in the field of city development is not yet clearly defined, but its evolutionary stage is such that one can predict with some certainty what it will be accepted as meaning within a few years. Within the past few years, it has been used to describe many municipal activities and programs, and it has been used synonymously with many other terms in the rapidly developing field covering governmental action to improve housing conditions. This semantic confusion has hindered communication among those groups interested in greater municipal concern over housing conditions and has frequently created antagonisms and overemphasized differences. Although this semantic confusion is unfortunate, it is understandable; the major groups that have evidenced interest in the field-including private business groups, planners, housers, and municipal officials-are quite divergent. Frames of reference differ among such groups as do their basic aims and goals. Each group tends to develop its own special terms-terms which tend to have esoteric meanings within the group. Communication among the groups is not great. In fact, several of the groups take diametrically opposed positions on major housing questions. This opposition tends to create suspicion of the other's aims and to preclude, or at least strongly discourage, agreement among the groups on aims, means, and terms.

But now that there is a definition of "conservation" in the Housing Act of 1954 (infra note 3; \$3II (c), 42 U.S.C.A. \$1 460 (c) (Supp. 1954)) and since cities are beginning to increase their housing improvement activities, these various terms are beginning to acquire generally accepted meanings. The use of a single term to define both a program and a particular action is not as prevalent as it once was, and one finds greater precision in their application. But some confusion still exists, and since this symposium on planning law has several articles in which these terms are used, it is well to define them carefully.

Conservation is a program to maintain the economic and social values of a neighborhood and, where desirable, to improve those values. Conservation accomplishes these aims by maintaining and improving the physical standards of the neighborhood -both private and public. Its aim is to maintain and improve the quality of the area's housing and public improvements. Its approach is neighborhood improvement -not just the improvement of a single structure-and it is concerned with basically sound neighborhoods-neighborhoods that are worth conserving. In accomplishing

* A.B. r940, M.A. 1943, University of Chicago. Planning Analyst, Milwaukee Board of Public Land Commissioners, 1944-r947; Milwaukee Municipal Reference Librarian, 1947-1948; Assistant Director, Urban Redevelopment Study, 1948-1950; Field Representative, Division of Slum Clearance and Urban Redevelopment, Housing and Home Finance Agency, x950; Assistant Director, National Association of Housing and Redevelopment Officials, since $x 950$. 
these aims, conservation may employ many tools-perhaps all of the tools defined below that have to do with improving housing and neighborhood conditions.

Of major importance in this definition is the neighborhood approach. Although it is possible to conserve a single structure or a group of structures, effective and lasting conservation is undertaken on a neighborhood, or planning area, basis. A prerequisite for a conservation program, therefore, is the existence of a plan for the neighborhood.

Thus the aim of conservation-viz., the achievement of a sound, well planned neighborhood-is quite similar to redevelopment, but of course the means differ considerably. Under conservation, preservation of existing structures and basic patterns is the means of accomplishing the end; under redevelopment the means is demolition and rebuilding. Under conservation, the neighborhood or area is basically sound; under redevelopment the neighborhood or area is basically bad-it is not worth preserving. Redevelopment is concerned with areas quite low in the scale of existing values; conservation is concerned with areas considerably higher in this scale of values. Generally there is a gap between the two; that is, there are areas neither high enough nor low enough in the scale to be susceptible to either kind of treatment.

The demolition of structures within a conservation area, however, is one of the necessary tools in a conservation program. It may be necessary to employ redevelopment powers to achieve this demolition, but for purposes of definition, this is not strictly redevelopment. Demolition and rebuilding on relatively few scattered parcels does not constitute redevelopment nor does the preservation of relatively few scattered structures in an area otherwise to be demolished constitute conservation.

"Housing law enforcement" follows "conservation" and "redevelopment" as the third term in this glossary. When this term is used, there is little confusion as to its meaning. The confusion arises from using other terms, such as "conservation" and "rehabilitation," as synonymous with "housing law enforcement." Housing law enforcement, or sometimes just "code enforcement," is a self defining term. It is the enforcement of municipal codes and ordinances that apply to housing. Such. codes and ordinances include the building code, zoning ordinance, electrical code, fire code, plumbing code, etc. In addition it includes what many cities call a "housing code"-a code of minimum standards for existing housing. It is the enforcement of this minimum housing standards code that is in the minds of most when the term "housing law enforcement" is used.

Housing law enforcement is a tool-not a program. It is frequently thought of as a program in itself because it is often (and rightly so) applied on an area basis to bring the standards of all housing in one area up to the prescribed minimum. The "Baltimore Plan" initially consisted of a housing law enforcement program on an area basis. The publicity given the "Baltimore Plan" has done much to alert cities to the importance of adopting minimum standards for existing housing and of 
enforcing such standards on an area basis. It is important to understand, however, that housing law enforcement on an area basis is not conservation although housing law enforcement may be a tool employed in a conservation program. The inherent limitations of housing law enforcement prevent it from achieving by itself the aims of conservation, and these limitations will be discussed later on.

"Rehabilitation" is the fourth term. It is perhaps the most widely misused term of all, being employed to mean conservation, redevelopment, and housing law enforcement as well as its more precise meaning-viz., the remodeling or renovation of an existing structure. Rehabilitation obviously results, although on a somewhat minor scale, from housing law enforcement; and this is the reason the terms have often been used interchangeably. Also rehabilitation is essential in a conservation program, and this too accounts for equating the two terms. Rehabilitation, however, has also been used to mean redevelopment; for in the early days of redevelopment, the two terms were often used to mean the same thing. Lately, the term "rehabilitation" has been used but infrequently to mean redevelopment.

Urban renewal is the most recent term in the glossary. It achieved its present prominence quite rapidly. Its first real use came from Miles Colean's book, $R e$ newing Our Cities. ${ }^{1}$ The term was picked up by, and gained further ascendancy from, the report of The President's Advisory Committee on Government Housing Policies and Programs. ${ }^{2}$ It was then incorporated in the Housing Act of $1954{ }^{3}$ Under the Housing Act of 1954 ( $\$ 3$ rI (c), 42 U.S.C.A. $\$ \times 460(c)$ (Supp. I954)), the term "urban renewal project" was defined to include "undertakings and activities ... for the elimination and for the prevention of the development or spread of slums and blight" and to involve "slum clearance and redevelopment ... or rehabilitation or conservation ... or any combination or part thereof. ..." Although the term had to be defined rather strictly in the legislation in order to limit the activities for which the Federal Government would provide financial assistance, the concept is quite clear. It is the broad, all inclusive term covering all the city's activities to eliminate and prevent the spread of slums and blight. Thus it includes all the terms already mentioned.

It should be pointed out that although public housing is not legally part of urban renewal under the Housing Act of I954, it is clearly a part of the urban renewal concept. It improves housing conditions by providing housing for low income families and eliminating through various methods a comparable number of substandard structures.

Urban renewal, then, is the over-all term, embracing the programs of redevelopment, conservation, and public housing and the use of the tools of rehabilitation and housing law enforcement. Urban renewal also presupposes a program of general

\footnotetext{
${ }^{1}$ Miles L. Colean, Renewing Our Cities (1953).

2 President's Advisory Committee on Government Housing Policies and Programs, Recommenda* tions on Government Housing Policies and Programs (i953).

3 Title I, Housing Act of 1949, as amended by Title III, Housing Act of 1954, 63 STAT. 414 (1949), as amended, 68 Stat. 622 (1954), 42 U.S.C.A. \$1450 et seq. (Supp. 1954).
} 
city planning; for without planning on a city-wide basis as well as a neighborhood or area basis, each of these programs and activities becomes an isolated, unrelated project. Thus, urban renewal is the city's program to eliminate and prevent slums and blight.

This somewhat lengthy discussion of terms is essential to indicate how these terms will be used in this paper and to place conservation in its proper perspective. But before getting into methods of carrying out a conservation program and the problems raised in such an undertaking, it would seem wise to define conservation further in terms of $(x)$ the kinds of areas where conservation is and is not the appropriate program and (2) a realistic appraisal of its potential.

\section{Conservation Areas}

In discussing areas suitable for conservation, it is necessary to create a "model"i.e., an area which contains all those elements that make it suitable for the kind of program here described. Probably no such "model" conservation area exists in any city, for in practice one finds areas to be mixtures of many things which require the use of more than one program to achieve urban renewal objectives. But nevertheless, where most of these conservation elements are present, the area can be treated primarily by a conservation program. Classifications are useful to indicate the major kind of treatment required, but it should always be recognized that nearly every area of any size will require more than one remedial program. ${ }^{4}$ But for purposes of describing the kinds of areas that are worth conserving, we will assume the fiction of homogeneity.

Time is the first and major element in selecting areas for conservation. A conservation program is aimed at prolonging the economic and social life of an area for a good many years-twenty-five, or even more. It is not a hold-the-line programa program aimed at maintaining the condition of the area at a relatively low level until the community amasses the resources to give it a drastic remedial treatment. There are such areas-areas that for various reasons should be cleared but which cannot be cleared and redeveloped without governmental assistance and which rate a rather low priority for treatment. Major investment in such areas would be foolish, but yet conditions cannot be allowed to threaten the health or safety of the inhabitants. In such an area, conservation would be unwise; but housing law enforcement to maintain minimum standards would be essential. Thus how long the community wishes to continue the use and pattern of an area is an essential criterion in determining whether an area should be conserved.

Another basic criterion is use. If an area is residential in character and if the city's land use plan shows the area for non-residential use, then conservation of the residential use would ignore the city's planning objective. Such an area creates a problem for the community, but conservation is certainly not the answer.

- For an excellent example of the classification of areas on the basis of the major kind of treatment required, see Broome County Planning Board, A Fight-Blight Plan for Binghamton, New York, General Plan Report No. 5 (1953). 
Land pattern is a third criterion. Hindsight is a wonderful attribute. It enables us to criticize our predecessors' lack of vision in laying out too narrow streets, too small lots, too many streets, etc. But it also means that we should not make the same error by preserving their mistakes. If the land pattern of an area is obsolete and basically bad, then the error is compounded if today we take steps to preserve it. The land pattern need not conform to the highest of present day standards to make it conservable, but certainly it must be acceptable and usable under present day conditions before it warrants investment in its continuance.

A fourth criterion is density. This is not so much the over-all density of the area, for a conservation program can do much to remedy such density deficiencies. This density is really land coverage. If the structures are so placed upon their parcels and are of such a size as to create a high density-a density in excess of acceptable standards-then conservation would merely tend to preserve this undesirable density. It might even increase the density because of the conversion of large units into smaller ones.

A fifth criterion is the economics of conserving the area. This factor will become more evident in discussing the elements of the conservation program, but here it should be pointed out that even though all the other factors are favorable, it may be financially infeasible to conserve the area-there may be no market for the structures in the area if it is conserved.

The sixth and last criterion is the obvious one-condition of the structures. If the structures in the area are of such a design or in such a condition that they do not warrant additional investment and are not worth conserving, then the area is not a suitable conservation area.

Emphasis has been placed upon negative criteria purposely. Too often conservation is suggested as a means of improving neighborhoods that are basically unsound. The emphasis is solely that of improving the condition of the structures themselves with little regard to the desirable use of the area, its land pattern, etc. Though the condition of the structures in the area is a major factor, it is not, by far, the only one.

Although these criteria have been stated negatively, they obviously may be stated positively as well, and when so stated constitute the criteria for selecting areas suitable for conservation.

\section{Conservation Potential}

The second topic that requires some discussion before getting into the techniques and problems of conservation is its potential. Here too it is necessary to take a somewhat negative approach in order to discredit the exaggerated claims that have been made for it. Conservation is often looked upon as a means of raising the economic level of an area. It is evident that this is possible; Georgetown in Washington, D. C., is the classic example. But areas such as these are the exception rather than the rule. They become socially desirable areas and considerable sums are invested in improving the structures. Only a very few of these older neighborhoods can be so 
transformed. The income stratification of the population will not be altered because of conservation activities; each economic group will have to live somewhere, and all areas cannot be transformed so that they will attract those with higher incomes.

It is unfortunate that emphasis is sometimes placed upon major upgrading in conservation areas, for it distorts the basic idea of conservation-viz., the preservation and improvement of the area so that it may serve a longer, more useful, and more desirable economic life. Improvement is to remedy existing deficiencies and to remove, partially at least, some of the obsolescence that is bound to be present. As newer areas are developed, they will generally attract the higher income groups from the older areas, and it is almost impossible to maintain an area for the same economic groups throughout its life. The purpose of conservation is to prevent deterioration of the area when this movement occurs by providing some of the elements (other than newness of structures) that make the new areas more attractive. Conservation is aimed at preventing such areas from becoming blighted.

\section{A Conservation Program}

The purpose of a conservation program is to remove those deficiencies that have made the area less desirable and to provide those amenities that make other areas more attractive. At the outset, it must be recognized that this is a relative goal, for age itself is a deficiency that cannot be overcome by a conservation program. Obsolescence takes place in the best of structures, and short of almost complete rebuilding, it cannot be remedied by conservation.

On the positive side, it should be noted that these older areas that are worth conserving have some attributes that make them more desirable that newer areas. Large shade trees, larger houses, less travel time to work, etc., are usual attributes of such areas. The purpose of conservation is to capitalize on these attributes and to provide as many as possible of the amenities present in the newer areas.

\section{Neighborhood Plan}

A major deficiency in these older areas worth conserving (they will be called conservation areas from here on) is the layout of the area-the neighborhood plan. Too many streets and a bad traffic pattern in many cases have caused the decline of the area. With subdivision regulations, the newer areas provide a much better traffic pattern and fewer streets. Curvilinear design has supplanted the gridiron pattern. Not much can be done with a gridiron pattern to change it into a curvilinear pattern, but something can be done to improve traffic conditions and remove some of the streets. The closing of some streets will force traffic to follow desired routes, and the land thus obtained can be used for small parks and play areas. Or it is possible to create pedestrian ways where streets once existed, the resulting green areas doing much to make the area more desirable.

Community Facilities

The neighborhood plan must also include provision for community facilities. 
It is not just a bad street pattern that has caused the relative decline of the area but the lack of community facilities as well. Land for parks and playgrounds is expensive in closer-in areas, and the setting aside of land for such purposes occurs much more frequently now than it did in the time these conservation areas were developed. Consequently, these conservation areas are marked by an absence of parks and playgrounds; the schools are usually aging and fail to provide the physical amenities of the newer schools in outlying areas. Children must cross major streets to get to school and there often is little or no land around the school for play purposes. Street lighting could be improved. Municipal services in general tend to become slipshod, reflecting the municipality's and residents' recognition of the area's declining character.

In short, the deficiencies in services and facilities supplied by the municipality are in part responsible for the area's declining character. The new plan for the conservation area, therefore, should include those community facilities necessary to bring it up to a desirable standard. Public expenditures in such areas may be sizable and should constitute a fair share of the capital improvement program. In short, the municipality should anticipate a major re-doing of community facilities in such areas.

\section{Demolition of Unsound Structures}

In these conservation areas, there are likely to be at least a few structures that are not worth rehabilitating. These are essentially slum structures, and their presence does much to accelerate the area's deterioration. Removing them can likewise do much to stimulate the area's improvement. The municipality may use its power of eminent domain in connection with providing public improvements to acquire such structures-replacing them with parks, playgrounds, new schools, etc--but this forces a neighborhood plan in which the location of these community facilities is dictated by the location of undesirable structures. Where the two can be made to coincide without detriment to the neighborhood plan, then a double purpose is achieved.

\section{Removal of Adverse Uses}

Many of these conservation areas were developed prior to the adoption of a zoning ordinance, and as a consequence, one finds scattered uses that do much to make the area less desirable. The classic example, of course, is the junk yard. A junk yard is never a thing of beauty; and when in the midst of a residential area, it naturally exerts an adverse effect. Rooming houses, improperly located taverns, business sandwiched between houses-these are further examples of improper land use that tend to detract from the area. Removing such adverse uses is difficult, unless, of course, they can be replaced by the new community facilities planned for the area, but their removal is important if the area is to be conserved. 
Rehabilitation of Structures

Improvement of the structures in a conservation area is really the heart of the conservation program. This is the aim of municipal activity in installing community facilities, replanning the area, removing the adverse uses, and demolishing the unsound structures. These activities are all aimed at making the area a more desirable residential area and encouraging the maintenance and improvement of the structures. In reporting out the Housing Act of x954, the Senate Banking and Currency Committee made it quite clear that a substantial improvement in housing conditions was the intent of the financial aid offered and that cities would not receive financial aid for community facilities unless such improvement resulted. ${ }^{5}$

Rehabilitation will generally take the form of modernization in such areas. The remodeling of kitchens and bathrooms, the removal of partitions, the installation of new heating plants, the improvement of exterior appearance-these are the kinds of rehabilitation activity one would expect in conservation areas. In addition, one might expect some conversions, altering large structures into smaller units. In conservation areas, the structures for the most part are basically sound-the defects are essentially those attributable to obsolescence rather than to major neglect. There will, of course, be some rehabilitation to correct inadequate maintenance-painting, new siding, etc.-but the major rehabilitation work will be primarily modernization to make the units more livable.

It is one thing to say that this kind of rehabilitation is what is necessary in conservation areas and another thing to bring it about. This is the major problem in any conservation program and how to achieve the kind of rehabilitation desired has not really been answered.

\section{New Construction}

It has long been considered inadvisable to build in older areas where the neighboring houses are well along in years. But if conservation is to improve an area, it must do something to encourage new construction. As Miles Colean points out in his book, ${ }^{6}$ the problem is to obtain renewal-the gradual replacement of the structures in the area. The aim of conservation is to encourage both rehabilitation and new construcion so that there will be a constant renewing of the area.

\section{Housing Law Enforcement}

Housing law enforcement standards are, by definition, minimum. They fall short of the standards that should be set for conservation areas. Housing law enforcement does improve structures, but it does not result in the kind of modernization and improvement contemplated under conservation.

At the same time, housing law enforcement is of value in a conservation area. There is always the problem of persuading the recalcitrant owner to bring his property up to the standards set for the conservation area. It is difficult under existing

\footnotetext{
${ }^{5}$ Housing Act of i954, Report from the Committee on Banking and Currency, Sen. Rep. No. 1472, 83d Cong., 28d Sess. 35-36 (1954).

Renewing Our Citres (1953).
} 
law to force him to cooperate. But one can force such an owner to bring his property up to the standards of the housing code, even though those standards are less than desired. It can be used to achieve some improvement.

Another useful function of housing law enforcement in a conservation program is the enforcement of occupancy provisions-provisions limiting the number of families that may occupy a given structure. A major cause of area deterioration is overcrowding-both of a dwelling unit and of a structure. It is evidence of too intensive a use and consequently of a probable milking of the structure by the ownerevidence of little or no interest in maintaining the structure. Law enforcement of this provision, therefore, is particularly useful in a conservation area.

Generally, however, the condition of the structures in conservation areas is better than that of the standards in the housing code. Housing law enforcement per se would do little to improve housing conditions in the area.

\section{Relocation}

The last element in a conservation program is relocation. People will be displaced by many of the actions in a conservation program-demolition, enforcement of occupancy provisions, installation of community facilities, removal of adverse uses, and rehabilitation. Community opinion will not generally accept the eviction of families if such families have no place to go. Consequently, a conservation program must at least consider the rehousing problem that will be generated.

The extent to which the community will and can assume responsibility for rehousing these displaced families will vary considerably. But as a minimum, a city can be expected to show some concern for these families and to provide some administrative device for assisting them in locating new quarters. Some cities may wish to go farther by providing financial assistance and, as under the urban redevelopment program, insisting that the quarters to which such families move meet the locality's minimum standards. Evidence would indicate a growing acceptance of public responsibility for assisting families displaced by government action.

These are the elements in a conservation program. A neighborhood plan, conforming to the master plan and providing for the installation of community facilities, demolition of unsound structures, removal of adverse uses, structural rehabilitation, new construction, housing law enforcement, and relocation. If all of these elements could be achieved, the result would be the rejuvenation of the area. The problem is how to achieve them.

\section{Legal Problems in Conservation}

Conservation presents municipalities with a new set of legal problems. In essence it is the problem of the extent to which private property rights have to give way to the public good as established by the municipality; for all of these problems go directly to the question of the authority of the municipality in dealing with private property. 
Under urban redevelopment legislation, the acquisition of slum property by a municipality and its disposition for private use is considered a public use or purpose within constitutional requirements. The public purpose is the removal of the slum because it endangers the health and welfare of the city's residents. It is also the carrying out of a plan that prevents future slums. In addition, under public housing legislation, the municipality has the authority to acquire either vacant or slum land for the purpose of erecting housing for low income families. The public purpose is the eventual destruction of the slums and the provision of housing for low income families. Also, under housing law enforcement, the municipality is exercising its police power in forcing owners and tenants to maintain their property in a safe and healthful condition, for to do otherwise would endanger the health and welfare of the inhabitants.

The constitutionality of these three actions has been well established. Urban redevelopment and public housing legislation have been upheld in numerous states, and the enforcement of minimum standards goes way back to the removal of nuisances. The courts have held that these actions are proper functions of the municipality.

Of the elements listed in the previous section, the first two raise no legal problems. Preparing a plan for the neighborhood is a standard municipal function and so is the installation of community facilities. The latter raises a problem of financing but certainly no legal problems. But all of the other elements do raise some kind of legal difficulty. Conservation raises new questions-questions that involve a greater encroachment on property rights-and we are now in the position of exploring possible solutions and determining the extent to which the courts feel it is proper for municipalities to go in attempting to improve living conditions.

One does not have to look far to find those who feel that the courts have already gone too far in encroaching upon property rights. For example, Charles F. Barnwell, writing in the Journal of Public Law about slum clearance and public housing, has this to say: ${ }^{7}$

The danger to be feared is quite basic, though perhaps unapparent. Study, whether superficial or intense, reveals the same obvious trend; a trend which, if followed to its logical conclusion, may well result in a greater blow to our democratic system than any lack of adequate housing-no matter how great; a trend which reveals that our courts are often too quick, too arbitrary, too unmindful of the ultimate consequences, in sacrificing or compromising the rights of individuals to make way for these projects of public purpose. The power of a sovereign to condemn slum areas to protect the health, safety, and morals of its citizens is not here questioned; nor is the power to appropriate private property for the public use when the land taken is the obvious, necessary choice for the proposed project. The extent to which legislatures have gone in providing for the arbitrary taking of private land and the liberal interpretations by courts of the inherent and acquired powers of the sovereigns to take private lands are the true dangers. For, as the scope of these powers is broadened by the courts, the rights residing with the individual are

${ }^{7}$ Note, Slum Clearance and Public Housing, 3 J. Pubuse Law 267 (1954). 
restricted or abolished. This writer submits that the contested taking of private land by any sovereign or its representative should be disallowed in all instances where such taking cannot clearly be shown to be a present public necessity; then the rights of the individual property owner shall prevail. If otherwise, the time may well be forthcoming when the owner of a Victorian home may suffer condemnation as a consequence of legislation requiring a more modern or functional design for buildings within his area.

Although the example of the condemnation of a Victorian house is somewhat extreme, the approach is basically that proposed under conservation where rehabilitation is undertaken through government action rather than through private voluntary action. The question, certainly, is a basic one-one that cannot lightly be ignored. At the same time, the problem of conditions within our cities and the increase rather than decrease in the size of these problems also cannot be ignored. Crowded areas, metropolitan problems, etc., all enlarge the scope of public necessity. Some means must be found to meet the problem. Perhaps the only solution is some sacrifice of individual property rights.

\section{Demolition or Repair of Unsound Structures}

Where a conservation area does contain structures that should be demolished because of their condition, the only tool available in nearly all cities is the police power. Under most codes, a house may be declared unfit for human occupancy because of health or structural deficiencies. Where it is a health question, it can be boarded up until the owner repairs or demolishes. Where it is a structural deficiency, it may be ordered demolished if it is unsafe, unless the owner wishes to repair. If the owner does not demolish or repair, then the city may have the authority to demolish, placing the cost of the demolition as a lien against the property.

Although the police power may be the only tool in obtaining the demolition of these structures, it is an imperfect tool. There is no assurance under health violations that the structure will be repaired or demolished. Non-occupancy is all that is required. And where the deficiency is a structural one, the city is usually reluctant to demolish on its own unless it is obviously necessary. As a result, in many cities one will find boarded up structures, uninhabited except by squatters. Such structures are likely to kill the incentive of neighboring property owners to improve their property. Some method is necessary to secure the removal or repair of these substandard structures.

One device that offers some hope is a law that requires the demolition of the structure if the repairs necessary to comply with the local codes amount to more than $5^{\circ}$ per cent of the value of the structure. Such a law was recently upheld by the North Dakota Supreme Court, ${ }^{8}$ and as a precedent it certainly holds some promise for the forcible removal of these structures. But when the repairs amount to less than 50 per cent, a method is needed to make sure such repairs are made. A possibility would

${ }^{8}$ Soderfelt v. City of Drayton, 59 N.W.2d 502 (N.D. I953). 
be a time limit within which the repairs would have to be made. If they are not undertaken within that time limit, the municipality would have the authority of repairing or demolishing, depending upon the condition of the structure, and placing the cost of the action as a lien against the property.

Repair of these structures, however, may not be the answer. In terms of the standards for the conservation area, repairs up to minimum standards may be inadequate and the structure may not warrant improvement to higher standards. A more promising method of obtaining the removal of these substandard structures, therefore, is the use of eminent domain under the redevelopment powers of the municipality.

Most redevelopment legislation has been written to provide for the acquisition of substandard structures on an area basis-that is, an entire area is acquired and cleared and the cleared land then disposed of for redevelopment. If such laws could be amended to permit the use of eminent domain to acquire scattered parcels of substandard structures in conservation areas, then it would be a relatively simple matter to acquire these derelict houses and, after their demolition, to dispose of the land for new construction. This would have the double benefit of removing the bad and providing the needed new construction in the area. It would also seem an acceptable procedure, for it is but an extension of the authority granted under redevelopment legislation.

An administrative problem would be created, however, in the selection of structures to be demolished. But even here, redevelopment offers precedent. Some redevelopment projects do not demolish all structures in the area. A decision has to be made as to which structures will be allowed to remain.

Illinois has passed legislation specifically authorizing such action-i.e., the use of eminent domain to acquire property in conservation areas. ${ }^{9}$ The city, through the Community Conservation Board, may acquire property (\$6) where it is necessary or appropriate for the "implementation of a conservation plan." The use of eminent domain for this purpose has been upheld by the Illinois Supreme Court. ${ }^{10}$ The case was sustained not on the ground that the public purpose was the clearance of slums but on the ground that the public purpose was the prevention of slums.

It is also contended that the "line of demarcation between a public and private use in the employment of eminent domain to eliminate slum areas . . . must be the elimination rather than the prevention of slums." But we are aware of no constitutional principle which paralyzes the power of government to deal with an evil until it has reached its maximum development. Nor is there force in the argument that if the use of eminent domain in the prevention of slums is permitted "every piece of property within the city or State can be condemned to prevent it from becoming a slum." Legitimate use of governmental power is not prohibited because of the possibility that the power may be abused.

${ }^{0}$ The Urban Community Conservation Act of 1953, ILL. Rev. STAT. c. 671/2 $\$ \$ 91.8-9$ r.16 (1954).

${ }^{10}$ People ex rel. Gutknecht v. City of Chicago, 3 Ill.2d 539, 545, I2I N.E.2d 791, 795 (1954). 
Use of the power of eminent domain rather than police action against owners of substandard property, however, raises a problem of equitable treatment. If eminent domain is used, the property owner is bought out; he receives cash for his substandard structure. If the police power is used, he is forced either to spend money to bring it up to standard or to spend money to have it demolished. He comes off second best to the man whose property was acquired under eminent domain. If juries in condemnation cases were not quite so generous, this might not be the case; but the fact is that illegal use and occupancy are not given sufficient consideration by juries in determining the amount of the award.11 If the municipality were to be more strict in the enforcement of its housing and occupancy provisions, the value of such property would probably decrease and so would the condemnation awards. The result might eliminate the question of inequitable treatment.

If such acquisition through eminent domain is a public purpose, however, there is equitable treatment. The happenstance of property location would determine whether eminent domain or housing law enforcement would be used to achieve the end being sought. The ends would certainly differ between a conservation program in a particular area and housing law enforcement activity in another area. Equitable treatment would be maintained within a particular program. Even now under redevelopment, there is this question of inequity depending upon location of property but it has not caused the courts to deny the public purpose of redevelopment.

\section{Removal of Adverse Uses}

Since an adverse use can often become a non-conforming use by amending the zoning ordinance, the question becomes that of removing non-conforming uses. One method which is found in several zoning ordinances is that of amortizing out such non-conforming uses-i.e., granting them a certain number of years for which the use may be continued but forcing discontinuance of the use at the end of the period. The theory is that within that period the use will be amortized and the owner will not have been deprived of his property without due process of law. The drawback to this arrangement is the time it takes to rid the area of these non-conforming uses. Even if the use were discontinued at the end of the period, 15 to 25 years is a long time to wait; and in the meantime, the non-conforming use continues to exert its adverse influence upon the surrounding property.

A far more practical, albeit more drastic, solution would appear to be the use of eminent domain to acquire the non-conforming use. The municipality would not have to acquire the land-just the use. The owner would be compensated for his improvements and the non-conforming use would be eliminated. The public purpose could well be the municipality's attempt to conserve the character and livability of the conservation area, and since the courts have accepted zoning as a proper

\footnotetext{
${ }^{11}$ See Housing and Home finance Agency, Admissibility of Evidence of Illegal Use or Condition of Property in Eminent Domain Proceedings (195r).
} 
exercise of the police power, the use of eminent domain to carry out that power should not have too rough sledding in the courts.

\section{Rehabilitation}

But the problems of removing substandard, derelict houses and adverse uses from conservation areas are simple compared to the problem of achieving the kind of structural rehabilitation desired in a conservation area. It is in the attempt to solve this problem that one comes up hardest against the traditional concepts of property rights. It is here that one pauses, wondering whether the solution offered creates more damage than the good achieved. For in advancing any positive method for achieving rehabilitation at the standards set for a conservation area, one must recognize that the property owner is to be forced to comply with standards that are higher than those of a minimum standards housing code. Such methods in general mean that he is required to rehabilitate his property in accordance with the standards set by a public body on the basis of what is considered desirable for the area. The idea of maintaining property values instead of the health or welfare of the inhabitants creeps into these proposals. It becomes a basic philosophic question as well as a legal one, and it is a question for which there is no prospect of an immediate solution. The states and their supreme courts will experiment with this problem until some form of equitable solution is reached. It would appear now, however, that our traditional concepts of property rights would have to give way somewhat in order to meet and solve the problems of our deteriorating older areas. That the courts seem to be moving in this direction is evidenced by the recent United States Supreme Court decision upholding the constitutionality of the District of Columbia Redevelopment Act. ${ }^{12}$ In this case, the Court said:

The values it [public welfare] represents are spiritual as well as physical, aesthetic as well as monetary. It is within the power of the legislature to determine that the community should be beautiful as well as healthy, spacious as well as clean, well-balanced as well as carefully patrolled.

Although the solution for rehabilitation in conservation areas is difficult, the problem is clear enough. In conservation areas, the rehabilitation desired is of a standard above the minimum standards of the housing code. It involves proper maintenance, painting, landscaping, etc. It involves the improvement of interiors to remove obsolescence-the old bathrooms and kitchens, heating plants, and the like. This is substantial rehabilitation and it is costly.

There are four basic approaches to achieving the desired rehabilitation: ( $x$ ) voluntary rehabilitation by property owners, (2) higher code standards for conservation areas than for other areas and enforcement through the police power, (3) public acquisition of property to be rehabilitated with disposition to private or public owners who will undertake the rehabilitation, and (4) public acquisition and rehabilitation of such property.

\footnotetext{
12 Berman v. Parker, 348 U.S. 26, 33 (1954).
} 
I. Voluntary Rehabilitation. It is this method that has received emphasis in the Housing Act of r954. It obviously does not involve legal questions concerning property rights. It is essentially an administrative problem. Initially, this will have to be the method followed by nearly all localities undertaking conservation programs. Other than in Illinois, state legislation does not now sanction more compelling measures, and it will undoubtedly take some little time for state legislatures to adopt, and for state supreme courts to rule upon, measures that give the locality some authority to require rehabilitation in conservation areas to standards higher than the minimum in the housing code.

Administratively the problem is to persuade property owners in a conservation area to rehabilitate their property to the standards established in the neighborhood plan. Nothing can be done under law to force the recalcitrant or impecunious property owner to rehabilitate to these standards. The city can only enforce the minimum standards housing code against such property owners.

But the city can take some steps to persuade the property owner to rehabilitate. By supplying technicians in the field of architecture and financing, the city may be able to demonstrate that it is to the property owner's advantage to rehabilitate. Also by pointing out the public improvements to be undertaken in the area, some propery owners can be convinced that such an investment is a sound one. Congress provided favorable terms for rehabilitation financing in conservation areas under section 123 of the Housing Act of I954 (adding \$220, National Housing Act, I2 U.S.C.A. \$I715 k (Supp. I954)), and this should provide encouragement to the property owner. But without some form of compulsion, the possibility of substantial success is somewhat remote.

Limited as it is, however, voluntary rehabilitation is a method that deserves consideration. It is the only method available; it may prove effective if the proper administrative tools are employed; and the result can be a much improved area.

2. Higher Legal Standards. This method employs the authority of the municipality to achieve the standards established as desirable for the conservation area. It may take two forms, neither of which has as yet been tried.

The first form is tied to the police power. The principle is to establish varying minimum standards for various zones within the municipality. Instead of having one minimum standard applicable to all housing in the city, this proposal would establish several levels of minimum standards. The city would then be zoned on the basis of these different standards. Thus the proposal is quite similar to a zoning ordinance where varying standards of lot coverage, set backs, minimum lot size, etc. are established for various areas. An additional variable in such a housing standards zoning ordinance could be time-the age of the structure would in part determine the standards it would have to meet.

Dr. E. R. Krumbiegel, Milwaukee's Health Commissioner, should be credited with first advocating such a proposal and in fact legislation was drafted to provide 
for it. But constitutional questions were raised, and the legislation was not introduced. ${ }^{13}$

The method, however, still offers some promise of using the police power to achieve standards of higher rehabilitation than that of the housing code without employing the power of eminent domain.

The second form of enforcing higher level standards differs from the former in the manner in which such standards would be established. Under the second form, these standards would be established by a commission or an authority having jurisdiction over a conservation area. This method has been advocated by the National Association of Real Estate Boards and appears in their proposed enabling legislation for the creation of conservation authorities. ${ }^{14}$ This proposal which appears in section $8-x$ of their proposed bill reads as follows:

A Conservation Authority may order the owner of a building or structure to make specific repairs or improvements in order to make the structures conform to ordinances containing health, safety, sanitary, and building regulations, and to a neighborhood conservation plan if the repairs and improvements are necessary in order to promote public health, safety and morals. The repairs or improvements so ordered shall be made at the expense of the owner. [Emphasis added.]

This method provides for greater flexibility than the former; but even with the safeguards of public hearings and city council approval of the conservation plan, there is still the danger that the courts will conclude that the standards established by such an authority are arbitrary. The Berman case (supra note 12) would indicate a trend toward supporting such legislation however.

The method provided for in the Illinois legislation does not permit the Community Conservation Board to establish higher police power standards for a conservation area but does provide the tools for achieving higher standards.

3. Public Acquisition; Disposition for Rehabilitation. The last two methods of achieving rehabilitation standards above those of the minimum standards housing code involve the use of eminent domain. They differ in the way in which the rehabilitation would be undertaken. In one instance, such property would be sold to private developers with stipulations that it be rehabilitated to certain standards. In the second instance, the property would be rehabilitated by the municipality itself, or a municipal authority and then disposed of.

The former method has already been employed by Philadelphia in the rehabilitation of one block by the Friends' Service Committee. The rehabilitation undertaken, however, was so drastic that it really constituted redevelopment rather than rehabilitation. The structures were gutted; essentially only the walls remained.

\footnotetext{
${ }^{13}$ For a more detailed discussion of this proposal, see Slayton, Urban Redevelopment Short of Clearance in Coleman Woodbury (Ed.), Urban Redevelopment: Problems and Practices 313, at 349-353 (1953).

it National Association of Real Estate Boards, Blueprint for Neighborhood Conservation (1953).
} 
The cost was close to the cost of new construction. ${ }^{15}$ Thus this kind of rehabilitation is considerably more drastic than that generally anticipated in conservation areas. This particular action has not been tested in the courts.

Chicago is the only city with legislation specifically authorizing this kind of action. Under the Illinois Urban Community Conservation Act, ${ }^{16}$ the conservation board is given the authority to ( $\$ 6)$ "acquire by purchase, condemnation or otherwise any improved or unimproved real property the acquisition of which is necessary or appropriate for the implementation of a conservation plan for a Conservation Area...." In disposing of such land, the "buyer or lessee must as a condition of sale or lease, agree to improve and use such property according to the conservation plan."

The Housing Act of 1954 would presumably permit this kind of action too, for in its definition of conservation and rehabilitation the following ( $3_{3 \mathrm{xI}}(\mathrm{c}), 4_{2}$ U.S.C.A. $\$ \mathrm{I} 460$ (c) (Supp. 1954)) is included: "(4) the disposition of any property acquired in such urban renewal area . . . at its fair value for uses in accordance with the urban renewal plan."

The principle of disposition for rehabilitation is the same basically as the principle of disposition of cleared land for redevelopment. One can anticipate a writedown in the cost of the property as in the case of urban redevelopment. But it does raise questions that are not easy to answer. If a write-down is involved in disposing of property for rehabilitation, it would seem only equitable to offer to resell the property to the original owner, giving him the benefit of the write-down. Under redevelopment, this is generally not practicable for replatting is usually the rule and the original parcel loses its identity.

A second question raised by this procedure is whether, in establishing rehabilitation standards for the conservation area, the municipality may be forcing an owner to give up his property and, even where it is allowed, effectively preventing him from reacquiring it for rehabilitation because of his financial inability to improve the property to the standards set for the area. Thus it can be claimed that this kind of arrangement discriminates against the financially limited property owner, forcing him to dispose of his property solely because of his economic station. This might easily be construed as using municipal authority to limit occupancy of an area to those with economic means above a certain level.

4. Public Acquisition; Public Rehabilitation. Perhaps because of the problems raised in disposition for rehabilitation, some advocate the use of eminent domain to acquire properties that are below the standards set for the conservation area and for some public authority to undertake the actual rehabilitation, disposing of the propery after it is rehabilitated. It is this procedure that is emphasized in the Illinois

\footnotetext{
${ }^{15}$ For a detailed description of this project, see Block Modernization, Philadelphia Slum Modernization, 93 Architectural Forum I72-I75 (1950); see also, Lammer, Rehabilitation Has Taken Three Forms in Philadelphia, 12 J. Housing 47, 49-59 (1955).

${ }^{26}$ See note 9 supra.
} 
Urban Community Conservation Act. The Act ( $\$ 6)$ gives the Conservation Board the authority to "hold, improve, mortgage and manage" properties acquired and spells out the procedure under which such properties will be rehabilitated by the Board: "provided that contracts for repair, improvement or rehabilitation of existing improvements as may be required by the Conservation plan to be done by the Board involving in excess of $\$ \mathrm{r}, 000.00$ shall be let by free and competitive bidding to the lowest responsible bidder. ..." Thus public rehabilitation is a definite and im. portant part of the conservation methods included in the Act.

Another form of public rehabilitation occurs when the municipality or a municipal corporation is given the authority to undertake repairs of property when the owner refuses to obey an order to make such repairs. The cost of such repairs becomes a lien upon the property. But where a municipality or municipal corporation may order repairs to standards above that of existing ordinances-repairs that are necessary to make the structure conform to the conservation plan-then the action is essentially that of public rehabilitation without public acquisition. The proposed enabling legislation of the National Association of Real Estate Boards contains such a provision. The section granting authority to require repairs to standards of the conservation plan has already been quoted. Following this provision, are a series of provisions spelling out the procedure for the Conservation Authority undertaking such repairs and placing the cost thereof as a lien upon the property.

With voluntary rehabilitation providing something less than a sure method of achieving rehabilitation of the structures in the conservation area and with zoned standards receiving little attention and of doubtful constitutionality, the trend seems to be towards either special standards set by a special authority or the use of eminent domain in some form to achieve rehabilitation. If eminent domain is to be used, a good deal of thought must go into justifying its use as a public purpose. Under urban redevelopment, the public purpose is the clearance of the slum-allowing it to continue would endanger the health and welfare of the city's inhabitants. The disposition of the land and its rebuilding, the courts have said, is incidental. Once the land has been acquired and cleared and provisions made so that it will not be misused in the future, the public purpose has been achieved. The fact that it is sold to private builders is not a misuse of the power of eminent domain; property is not taken from one and given to another. Where rehabilitation is the end product and where the conditions of the structures in the area are not definable as "slums," no slum clearance is involved. The public purpose must be the prevention of the area from becoming blighted. The public purpose is to prevent rather than to remove. This is a considerable extension of the public purpose concept.

The first case involving this principle has already been cited (supra note ro). It is an important precedent but it is not necessarily true that other state courts will follow this example. Some state supreme court decisions on redevelopment cases would indicate that they would not go this far. Generally, the Illinois Su- 
preme Court has been liberal in its interpretation of public purpose in connection with slum clearance. It is one of three states that has held that predominantly open land-dead subdivisions-may be acquired by eminent domain and redeveloped. ${ }^{17}$ It was also an early state in declaring slum clearance and urban redevelopment a public purpose.

A more cautious approach to the use of eminent domain in conservation areas might be the acquisition of a limited interest rather than the entire property. In some redevelopment projects, the redevelopment agency has bought a limited interest in some of the property, property not to be demolished but still requiring some kind of remedial treatment. The owner agrees to use the property in certain restricted ways and to make certain improvements and the redevelopment agency compensates him for relinquishing this interest. Under conservation, this kind of limited acquisition might prove workable-with the property owner agreeing to restrict the use of his property and to rehabilitate it in certain ways. Or if he does not agree, then the municipality or some municipal corporation has the right to condemn these rights.

It would appear, however, that the only means of assuring complete adherence to the conservation plan and of achieving rehabilitation to the standards established in the plan is through the use of the power of eminent domain in connection with those properties where the owners are unwilling or unable to cooperate. The basic question is whether the use of the power of eminent domain for such a purpose is a public purpose-whether property is being taken without due process of law. In such cases it would seem wise to employ the power of eminent domain sparingly at first and, where possible, authorize a more limited form of eminent domain than the authority now available under redevelopment. In short, to authorize authority that is too far in advance of current thinking, is to jeopardize the entire concept. At the same time, it must be recognized that unless municipalities are granted greater authority over the maintenance of sound living conditions, they will be unable-as they now are-to cope with the increasing problem of slums, blight, and deterioration in larger and larger areas.

Before leaving rehabilitation, one further problem should be discussed. This is the problem of applying current building code requirements to rehabilitation construction. If no rehabilitation occurs, the city accepts the standards of the existing structure so long as it meets minimum housing code requirements. As soon as rehabilitation occurs, however, the house is no longer acceptable. All new work must conform to present building code regulations. New plumbing must meet today's requirements. So must new wiring, new walls, etc. On the face of it, this seems inequitable. An extreme example involves window area to floor area ratio. Many older houses have dark entrance halls, separated from the living room

\footnotetext{
${ }^{17}$ People ex rel. Gutknecht v. City of Chicago, 414 Ill. 600, III N.E.2d 626 (1953); Redcvelopment Agency of the City and County of San Francisco v. Hayes, 122 Cal.App.2d 777, 266 P.2d 105 (1954), cert. denied, 348 U.S. 897 (1954); Oliver v. City of Clairton, $374 \mathrm{~Pa}$. 333, 98 A.2d 47 (1953).
} 
by a non-load bearing wall. Removal of this wall results in enlarging the room and improving the house generally. Its removal, however, may violate the window area to floor area ratio and necessitate enlarging the windows as well.

Application of the building code to rehabilitation work, therefore, can create many problems, increase costs, and discourage the operation. A solution would be building code standards for rehabilitation. This is easy to propose, though hard to achieve for it too creates problems. But it is a solution that has much promise, and city officials should attempt drafting building codes that will apply to rehabilitation work.

\section{Relocation}

As pointed out earlier in discussing relocation, a conservation program will result in the displacement of people. Enforcement of occupancy provisions, displacement during major rehabilitation, demolition, and moves because of inability to pay increased rents-all force the movement of people. Most families in conservation areas will have sufficient incomes to permit them to move to quarters that are decent, safe, and sanitary. So the relocation problem in conservation is not that of trying to rehouse families of low income. The problem is that of assisting the families thus displaced to find new quarters. Relocation responsibility is a standard requirement in the federal urban redevelopment program and some cities seem to be accepting greater responsibility for housing families displaced because of governmental action.

The legal problem is the recognition that such assistance is a legitimate local expenditure and that public funds can be so used. Other than in redevelopment legislation, there is little if any legislative recognition of relocation as a legitimate use of tax funds. There would seem to be no great legal hurdles to obtaining such legislative sanction. Such legislation should authorize assistance in the form of administrative help in finding suitable quarters and, in some instances, direct financial assistance to such families for moving expenses.

\section{Financing}

There are two kinds of financing problems that arise under a conservation program. One is municipal finance; the other individual finance. How does the city finance the work it must undertake in connection with a conservation program and how does the individual finance the rehabilitation of his house?

The municipal financing problem arises in providing the needed community facilities and in meeting the cost of rehabilitation operations that result in a loss. Also administrative costs may not necessarily be low since a good deal of service is contemplated in a conservation program-particularly where a program of voluntary rehabilitation is carried out. These items add up to a sizable amount for a city that wishes to pursue an active program, and with cities hard pressed for funds, a device to produce such funds would be helpful.

The special assessment is an approach some have proposed. Usually it is limited to the area being conserved on the theory that that particular area is the one to 
receive the benefits and that therefore it should be the area to pay for the improvements. Politically, this proposal is not likely to get very far. Residents of such areas will soon object, and conservation programs will tend to be discouraged. It also seems inequitable to assess the owners in the area for improvements when such owners have for years been paying for improvements in outlying areas. Improvements being provided in the conservation area represent deferred construction and are no less important than improvements in newer areas.

A second proposal for paying the municipal costs without raising taxes is to make use of the increased revenue that is anticipated from the improvement of the area. It is logical to assume that property assessments will be increased as a result of the rehabilitation of structures in a conservation area, and an earmarking of such increased taxes to pay for the municipal costs sounds reasonable. Whether the increases would equal the municipal costs is hard to say, but they would at least reduce them. One device might be the issuance of revenue bonds and the pledging of the increased taxes for their repayment. Whether a legal device is used to relate expenditures and increased income, the relationship is a valid one and is useful in demonstrating the soundness of undertaking conservation programs. At the same time, it is an argument that some use against improving their property-the fear of increased taxes. ${ }^{18}$

The National Association of Real Estate Boards proposes federal insurance for conservation area bonds in order to produce lower interest rates and better marketability. These conservation area bonds would be used to provide the needed public improvements and to pay for the acquisition of the property needed to carry out the conservation plan. ${ }^{19}$

Unless cities are provided with some means of raising additional revenue for the needed public improvements in conservation areas, there is not likely to be much conservation. One bright hope, of course, is the Housing Act of $1954(\$ 305,42$ U.S.C.A. \$1453 (a) (Supp. 1954)) which provides for a federal grant covering twothirds of the cost of the project. Included within the cost of the project are the necessary public improvements as well as the administrative and planning costs and the write-down in the disposition of property. This provides a considerable incentive to cities to undertake conservation programs and would seem to make it possible for any city with a real will to undertake a conservation program to do so.

Individual financing, however, is another question. There is no federal grant to the impoverished property owner. The Federal Government cannot pay twothirds of the cost of rehabilitating his home. The inability of the home owner to finance the rehabilitation creates a major stumbling block and often forces one to seek solutions that bring governmental authority into the picture.

\footnotetext{
${ }^{18}$ Some have proposed non-assessment of increased value created by rehabilitation. The thcory is that assessment discourages property improvement. This proposal is unsound on the face of it but it is cited as an example of a tendency to put rehabilitation in the center of municipal functions and misuse other municipal functions to support rehabilitation.

${ }^{10}$ Blueprint for Neighborhood Conservation, op. cit. supra note I4.
} 
Where the financing problem, however, is one caused by difficulty in obtaining loans because of the character of the area, then there are solutions. Under the Housing Act of 1954 ( $\$ 123, I_{2}$ U.S.C.A. \$r715k (Supp. 1954)), mortgage insurance is provided for the rehabilitation of houses in areas approved by the Federal Government as appropriate for urban renewal projects. So long as the city is carrying out a federally approved conservation plan in the area, FHA is authorized to insure mortgages in the area. Also the Housing Act of 1954 provides for open end mortgages, an arrangement under which the amount of the existing mortgage may be increased to provide funds for improving the property.

The fact that financing is available does not answer the basic question of individual financing. The question of individual financing is dependent upon the decisions of the community on the standards for the conservation area. Where the standards are not raised too high for the present occupants, a good deal of assistance can be given in the way of advice on arranging the family's finances to permit investment in the improvement. Also, one finds that many families can afford to pay higher amounts for housing and that it then becomes a question of values-placing a higher value upon better housing than upon the consumption of other goods.

\section{New Construction}

One cannot, of course, force individuals to build in these conservation areas: one can only demonstrate that it is economically sound to do so and, by providing the necessary community facilities, achieving the proper rehabilitation of the structures, and providing favorable financing terms through FHA, make it desirable to do so. In addition, the municipality can through its redevelopment and public housing powers undertake new construction in these areas on its own. If there is a pocket of slum structures in the area, the municipality may clear it under its redevelopment legislation and provide for the construction of new residences by the redeveloper. With its authority to erect public housing, the municipality may again construct public housing units in the area. In this instance, it does not necessarily have to clear part of the area but can build on scattered vacant lots if any are available. Through these two methods, the municipality can demonstrate that it is desirable to undertake new construction in the area and provide the environment that will encourage new construction in adjacent locations.

Most redevelopment laws provide for slum clearance and urban redevelopment on an area basis. Some even specify a minimum area. An immediate legal problem then is the amending of legislation to permit scattered acquisition. But in carrying out a program of scattered acquisition for slum clearance and urban redevelopment, one opens himself to the charge of arbitrary determination of the structures to be acquired. Where slum clearance and urban redevelopment is undertaken on an area basis, the courts have held that standard structures may be acquired so long as the character of the area itself is blighted or slum. Thus the taking agency, the redevelopment agency, is spared the decision of judging among those houses to be 
acquired and those to be passed up. The agency cannot be accused of arbitrary determinations. But under selective acquisition and clearance, the charge is bound to be made. Citizen $A$ points out that his house is better than citizen $B$ 's but that his, rather than $B$ 's, is being acquired.

If the problem of standards to determine selective clearance can be met, then the slum clearance and urban redevelopment process would seem particularly useful in providing the necessary new construction. Rebuilding would be by private enterprise except in those instances where the new use was public housing. The problem of encouraging the private enterpriser to undertake construction on these scattered parcels in the conservation area is met by ( $I$ ) selling him the land at a price that will make it feasible for him to undertake the construction and by (2) having under the Housing Act of 1954 a provision of mortgage insurance specially designed for new construction in conservation areas.

These then are the basic legal problems raised in a conservation program. Their solution is not simple. To resolve them requires basic philosophic decisions-the kinds of decisions that should not be made quickly. They will require court deliberation and vigorous discussion before a settlement is reached. The problem's difficulty is the importance of the two alternatives-a lessening of the individual's property rights on the one hand, the continued deterioration of cities and housing on the other. The conflict is real; the decision difficult. Probably, as in the past, compromise of some sort will be the answer.

\section{Administration Organization}

Something should be said about the administration of the conservation program, for such a program creates new and difficult administrative problems for the city. In addition, the number of proposed solutions to this question is considerable. Many solutions have specific champions-champions carrying considerable weight but unfortunately not always well versed in local government.

There are two questions of administrative organization; one dependent upon the solution of the other. The basic question is whether the authority for undertaking a conservation program should be vested in the city or given to a new independent authority with considerable powers of its own. The second question is that of the administrative organization within the city itself if the decision is to vest the authority for the program in the city.

\section{City vs. Separate Authority}

The arguments of those who advocate a separate municipal authority with considerable municipal powers are based upon the failure of the cities to undertake such programs and upon the necessity of coordinating many municipal functions in one area -a conservation area. A further argument is that a separate authority with independent powers will be free from political control and pressure and therefore can accomplish the job more efficiently and effectively. 
The National Association of Real Estate Boards is the major champion of the separate, independent authority concept. In Blueprint for Neighborhood Conservation, they propose an independent authority with considerable independent power. In presenting their proposal, they state: ${ }^{20}$

Neighborhood conservation requires added municipal powers in law enforcement, in levying of benefit assessments and taxes, and in acquisition of property or uses or portions of properties.

It requires the use of these powers in coordination with such municipal functions as planning, zoning, and platting of land. In addition, it requires close cooperation with city boards and departments governings schools, parks, recreation facilities, libraries, sanitary services, streets, and sewers.

Success of the program depends upon effective coordination of all these diverse kinds of work. Existing city departments have their city-wide functions and should not be disturbed or expected to absorb the major responsibility of carrying through neighborhood conservation programs.

To provide the proper administrative framework for effective neighborhood conservation, it is proposed that the state legislatures enable the cities to create a new arm constituted something like a school board, to do this particular job.

The powers proposed for the conservation authority include the power of eminent domain, the power to enforce building and housing codes in the conservation area, the power to issue neighborhood conservation bonds to provide funds for public improvements and to acquire the property necessary to carry out the conservation program, the power to levy benefit assessments, the power to levy a city-wide tax, the power to contract with the Federal Government for the insurance of neighborhood conservation bonds, and though not specifically stated, the power to prepare the plan for the area. These are considerable powers and no check by the municipality is provided other than that of appointment of authority members by the mayor.

Such an authority would have many of the powers of the city and would in effect provide an additional municipality but with none of the city's democratic controls; that is, the separate authority would not be responsible to the voters. The NAREB proposal is used as an example; other organizations have proposed somewhat similar arrangements, particularly the National Association of Home Builders.

The opposing position states that the problem is essentially that of coordinating existing municipal functions-not an impossible task by any means-and that the creation of a separate authority to undertake a specific job creates a difficult problem of coordination in itself since it would be duplicating many of the municipality's functions. The case for use of the existing municipal structure to undertake a new municipal activity rather than vesting such an activity in a specially created inde- 
pendent authority was stated by Herman G. Pope, executive director, Public Administration Service, at a conference on conservation and rehabilitation: $:^{21}$

The case for integration of local government functions is impressive in many jurisdictions. Reasonable integration of any municipal function with the existing municipal government structure can be supported on a number of counts. One of these counts rests on the premise that responsible and responsive democratic government requires that dispersion of responsibility and of policy making authority should be held within reasonable limits. The existence of too many autonomous and semi-autonomous governmental agencies complicates local government to the point where the average citizen loses interest and capacity to understand it. ...

Also, where the fragmentation of local government occurs, the various fragments are all too often only indirectly responsible to the public. Members of governing boards and commissions may be appointed by various authorities or combinations of authorities and instances can even be found where such boards and commissions are self-perpetuating. The existence of autonomous boards, commissions, and authorities complicates enormously the problems of local government coordination.

To students of public administration it would seem that the weight of the evidence is on the side of the conservation program becoming integrated with the regular municipal corporation rather than being administered by a separate, independent authority. Where a program such as the conservation program requires the exercise of so many of the existing functions of the municipality, it would seem more than unwise to create a new and duplicating agency to carry out the program.

\section{Administrative Organization Within the City}

There is, as might be expected, a good deal of variation among the proposals for administration of the conservation program where it is to be administered by the city. The proposals, however, fall into two basic categories: (I) the creation of a new department with authority to exercise functions of other departments within the conservation area (some propose to give such a department greater autonomy than existing departments), and (2) the use of existing departments to perform the necessary functions with coordination provided through a coordinator. A third possible position, and one that some cities may follow, is to make no administrative changes but to rely upon interdepartmental coordination to carry out the program properly.

The particular type of administrative organization depends upon the city itself; the ability and authority of those in positions of authority; and the traditional way of handling administrative problems. Many ways can be successful. It is more important to emphasize the administrative problems than to propose a pat solution.

The basic administrative problem of a conservation program is that of coordination. Many municipal functions will be performed in a conservation area. Their

${ }^{21}$ National Round Table Conference on the Role of Conservation and Rehabilitation in Community Development, April 28-30, 1954, Chicago, Ill., sponsored by the Public Administration Clearing House, the American Society of Planning Officials, and the National Association of Housing and Redevelopment Officials. 
timing is important. They will be performed by many departments. Some functions will be comparatively new. The Federal Government will probably be involved and will have to be satisfied periodically that the program is progressing as planned.

Specifically, a plan will have to be prepared for the area. This will involve commitments from those departments that supply community facilities-the school board, the highway department, the park board or department, etc. Each will have to include the improvements in its program and will have to be told when the improvement is to be installed. Land will be acquired. Determinations will have to be made as to which areas are to be rehabilitated, which to be acquired and demolished. The agency that works on rehabilitation will have to know the decision on what is to be acquired. If housing law enforcement is used, the enforcement agency must plan its inspection program in conjunction with the agency undertaking rehabilitation. It too must know the decisions on property to be left and property to be acquired. Someone in authority must be able to execute contracts with the Federal Government and have the authority to contract to perform certain specified actions. All these activities require some coordinating device, some directing authority with sufficient authority to obtain action-in short, responsibility for the program must be identifiable.

Several cities, notably Chicago and Philadelphia, have hit upon the housing and redevelopment coordinator as the device for achieving such coordination. In each instance, the office is directly responsible to the mayor and has the authority of the mayor behind it. Other cities are exploring this possibility.

Chicago also has established a Community Conservation Board to select conservation areas and plan the conservation program in such areas. The Conservation Board has been given considerable authority but unlike most housing authorities and redevelopment agencies it is not an independent agency but is part of the city government.

Where the city has a city manager, it has been proposed that an assistant to the city manager in charge of the conservation program be appointed. Cincinnati has suggested this procedure. Other cities tend to rely upon established agencies, such as the redevelopment agency, to be responsible for the execution of the conservation program.

The pattern, however, is fairly clear. The coordination of all the functions required in a conservation program necessitates centering authority and responsibility. The precise location is immaterial; but some one agency or individual must be given the responsibility. If the program fails, he is responsible; if it is successful, he receives the credit.

In summary, the administration of the conservation program creates no problems new to public administration. It intensifies the problem of coordination but not to the extent where an administrative device cannot be found to solve it. Centralization of authority and responsibility is essential but not to the point of separating the conservation agency from the rest of the city government. 
A word should be said about the role of the planning commission in the administration of the conservation program. In addition to the delineation of areas in the city on the basis of the kind of remedial treatment or treatments required to improve them, the planning agency must also prepare at least general plans for each conservation area. In addition it must gear its public improvement program to the needs of these conservation areas. It must decide, or at least recommend, those areas to be blessed and those areas to be slighted when it comes time to deal out the money for public improvements. All planning agencies should be exercising such functions now, but with the advent of a conservation program, they will be forced to. They will have to make decisions and stick by them. In short, they will have to do a good deal more planning and will have to be a good deal more decisive than they have in the past. The planning decisions are the major decisions and they will have to be made early in the program.

\section{SUMMARY}

The administrative problems of conservation though difficult are not insurmountable. The cost is not small but federal financial aid is available. The program seems essential if American cities are to solve the problem of gradual (and sometimes precipitous) deterioration of neighborhoods. Effective conservation programs would seem to require some further lessening of individual property rights. Does the public good emanating from a conservation program outweigh the lessening of these property rights? The question is for the people through their legislative bodies and their courts to decide. The alternatives-gradually deteriorating cities or diminished individual property rights-are not pleasant. Perhaps, as before, the answer lies in compromise-a modified conservation program with somewhat diminished property rights. 